score of 390 in 2009 meant one was in the 15th percentile. In 2010, however, that same scaled score meant one was in the 31st percentile. One will note other significant differences when scanning Table 1 as well.

Interestingly, many examinees can recall their percentile ranking but cannot recall their scaled score. It is easy to understand why some examinees may be interested in learning how well they performed relative to their peers. Yet, from the example shown above, it is evident that percentile rankings may be misleading for both examinees and the general public. When the ranking portrays the examinee as being more knowledgeable than he or she truly is, it inflates and misrepresents one's perceived ability and misleads the public. For example, consider an MC-FP candidate in 2010 that scored a 450 on the exam and wants to compare the ranking with other candidates. This examinee would rank in the 51st percentile among his or her MC-FP peers, but only in the 40th percentile when compared with candidates seeking initial certification.

The practice of reporting percentile rankings has the potential to introduce other undesirable elements into the score reporting process as well. For example, the very nature of reporting percentile ranks will no doubt mean some people will be pleased with their ranking, while others will not. After all, persons at the top end of the scale will certainly feel great about themselves knowing they outperformed the vast majority of their peers on a national examination. However, for those unfortunate examinees that happened to fail the exam it can be rather embarrassing to realize that say, $96 \%$ of one's peers performed better than he or she did. When an examination is criterion-referenced, the only thing that really matters is one's performance relative to the minimum passing standard. After all, someone that scores a 500 on the MC-FP examination is not "more certified" than someone that passed with a score of 400 . We contend that through reporting scores properly and directing examinees toward the appropriate criteria for making meaningful inferences, we can be more responsible with our score reporting while concurrently preserving the dignity of those that inevitably fail

Kenneth D. Royal, PbD, and James C. Puffer, MD
SOCIETY OF TEACHERS OF From the Society of Teachers
FAMILY MEDICINE of Family Medicine

Ann Fam Med 2013;11:187-188. doi:10.1370/afm.1527.

\section{STFM EXAMINES ITS GOVERNANCE STRUCTURE}

STFM has begun a careful study of its governance structure. The goal is to ensure that the Society is making the most effective decisions in the most efficient way possible and that the decisions are in the best interests of the organization and its members. Governance refers to the way in which decisions are made within STFM and involves actions of the Board and committees, especially as they involve allocation of STFM's resources. A governance task force has been charged with the responsibility for making recommendations to the STFM Board. The members of the task force offer a balance among past and current leaders, as well as members of the current STFM Board and committees.

\section{Task Force Members}

Victoria Gorski, MD, Montefiore Medical Center, Governance Task Force chair

Stacy Brungardt, CAE, Society of Teachers

of Family Medicine, Leawood, Kansas

Dan Castro, MD, Harbor UCLA Medical Center,

Torrance, California

Sam Cullison, MD, Swedish FMR Cherry Hill

Campus, Seattle, Washington

Scott Fields, MD, MHA, Oregon Health \& Science

University, Portland, Oregon

Melly Goodell, MD, Medstar Franklin Square

Medical Center, Baltimore, Maryland

Larry Halverson, MD, Cox Health FMR,

Springfield, Missouri

Jeri Hepworth, PhD, University of Connecticut

St. Francis Hospital Family Medicine Residency

Program, Hartford, Connecticut

Ben Miller, PsyD, University of Colorado,

Denver, Colorado

Beat Steiner, MD, MPH, University of North Caro-

lina, Chapel Hill, North Carolina

Rick Streiffer, MD, University of Alabama,

Tuscaloosa, Alabama

Mary Theobald, MBA, Society of Teachers

of Family Medicine, Leawood, Kansas

STFM has not begun this project because of any major problems or concerns. Just as it is good practice for patients to receive periodic check-ups regarding their health, it is also a good practice for STFM to 
assess its organizational health. The present moment was chosen for this analysis because, in fact, STFM is quite healthy and thinking about how to best take advantage of this in light of some organizational transitions (eg, losing one CAS representative on the board).

Just as we compare a patient's health to a set of standards and goals, STFM will be comparing its governance structure to a set of standards referred to as "performance requirements." The performance requirements were recently developed by the governance task force and approved by the STFM Board of Directors. They are informed by STFM's mission and values and highlight the need to be responsive to STFM's strategic plan.

The next step for the governance task force will be to compare STFM's current governance structure (what is) with the approved performance requirements (what should be). This will identify problems or gaps: critical differences between what is and what should be. The gaps will be presented to the Board when it meets in May 2013.

After the gaps are identified and agreed upon by the Board, the task force will develop potential solutions to the identified gaps. Those solutions will be shared with the STFM community: elected and appointed leaders and the general membership. By allowing for broadbased input, STFM will increase its chances for developing the best solutions to the identified problems.

STFM is committed to make those changes that will result in the most responsive and effective organization possible. While change for change's sake will not happen, STFM will not shy away from making change where needed. The process will be improved with thoughtful input from STFM's leadership and its members.

If you have any questions or comments please feel free to contact me at vgorksi@montefiore.org or STFM Executive Director Stacey Brungardt, CAE at sbrungardt@stfm.org.

Victoria Gorski, MD Chair, STFM Governance Task Force

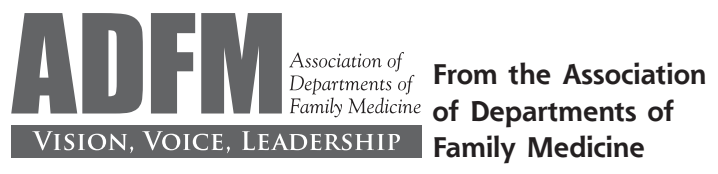

Ann Fam Med 2013;11:188-189. doi:10.1370/afm.1523.

\section{INTERPROFESSIONAL EDUCATION}

The proposed Liaison Committee on Medical Education (LCME) Accreditation Standard ED-19-A states: "The core curriculum of a medical education program must prepare medical students to function collaboratively on health care teams that include other health professionals. Members of the health care teams from other health professions may be either students or practitioners."

The rationale for this new standard is that interprofessional education (IPE) and practice leads to improved patient outcomes, enhanced safety and quality of care. ${ }^{1}$

The broader range of competencies required for interprofessional collaboration (beyond the common competencies for health care professionals and the individual competencies specific for various disciplines) include interprofessional communication and teamwork around patients and populations, specific values and ethics, and roles and responsibilities for collaborative practice. "Interprofessionality" has been defined (Amour and Oandasan 2005) as the "...process by which professionals reflect on and develop ways of practicing that provides an integrated and cohesive answer to the needs of the client/family/population ${ }_{i} .$. [it involves] knowledge sharing...optimiz(ing) the patient's participation...unique characteristics in terms of values, codes of conduct and ways of working."

IPE is not a new concept:

- The Centre for the Advancement of Interprofessional Education (CAIPE), in 1987 defined IPE as occurring "when 2 or more professions learn with, from and about each other to improve collaboration and the quality of care ${ }^{1 / 3}$

- Two decades later, Health Canada (with the Association of Faculties of Medicine of Canada) developed a method of integrating IPE into professional accreditation, leading to the formation of the Accreditation of Interprofessional Health Education (AIPHE) ${ }^{4}$

- The World Health Organization (WHO) published their "Framework for Action on Interprofessional Education \& Collaborative Practice" in 2010. ${ }^{5}$ They explained, utilizing evidence-based research, how IPE and collaborative practice could become a strategy to transform health systems globally ${ }^{6}$

While IPE has achieved broad support, including reinforcement through the patient-centered medical home model and the Affordable Care Act, commitment to this educational model is not universal. In addition to the "silos" that resist the transformation needed for full scale adoption of IPE, barriers to its adoption include communication, conflict resolution, time constraints, attitudes of team members, and presence or absence of resources like electronic health records. ${ }^{5}$ Evaluation of teaching and learning can include instruments measuring degree of collaboration, ${ }^{7}$ as well as ultimately the effectiveness in improv- 